\title{
Randomized double-blind controlled clinical trial of the blood pressure- lowering effect of fermented milk with Lactococcus lactis: A pilot study ${ }^{1,2}$
}

\author{
Lilia M. Beltrán-Barrientos, ${ }^{*}$ Aarón F. González-Córdova, ${ }^{*}$ Adrián Hernández-Mendoza, ${ }^{*}$ \\ Eduardo H. Torres-Inguanzo,† Humberto Astiazarán-García, ${ }^{*}$ Julián Esparza-Romero, ${ }^{*}$ \\ and Belinda Vallejo-Cordoba*3 \\ ${ }^{*}$ Centro de Investigación en Alimentación y Desarrollo, A.C. (CIAD), Carretera a La Victoria Km. 0.6, Hermosillo, Sonora, Mexico, 83304 \\ †Hospital Privado de Hermosillo, S.A. de C.V. (Hospital CIMA Hermosillo), Hermosillo, Sonora, México 83280
}

\begin{abstract}
The blood pressure-lowering effect of fermented milk with Lactococcus lactis NRRL B-50571 was evaluated in a double-blind randomized controlled clinical trial with prehypertensive subjects. Participants were randomized into 2 groups ( $\mathrm{n}=18$ each group): one group treated with fermented milk with Lactococcus lactis NRRL B-50571 and a control group treated with artificially acidified milk. Results revealed that during daily consumption of fermented milk for $5 \mathrm{wk}$, systolic [(116.55 $\pm 12.26 \mathrm{mmHg}$ vs. $124.77 \pm 11.04 \mathrm{mmHg}$ ) and diastolic blood pressure $(80.7 \pm 9$ vs. $84.5 \pm 8.5 \mathrm{mmHg})]$ from the fermented milk group was lower than the control group. Additionally, triglyceride, total cholesterol, and low-density lipoprotein in blood serum were lower in the fermented milk group than in the control group. Results demonstrated that daily consumption of fermented milk with Lactococcus lactis (NRRL B-50571) had a blood pressure-lowering effect on prehypertensive subjects. Regular consumption of this product may be used as a potential functional food.
\end{abstract}

Key words: hypertension, Lactococcus lactis, fermented milk, clinical study, functional food

\section{INTRODUCTION}

Hypertension is a chronic degenerative disease that affects 1 billion people over the world and is a leading cause of death worldwide (WHO, 2013). Uncontrolled hypertension promotes chronic damage of the vascular system, myocardial strokes, and cerebrovascular insuf-

Received May 18, 2017.

Accepted September 16, 2017.

${ }^{1}$ This study was supported by the Mexican Council of Science and Technology (CONACYT; México City, Mexico) research project 240338 CONACYT.

${ }^{2}$ The authors hereby declare no conflict of interests.

${ }^{3}$ Corresponding author: vallejo@ciad.mx ficiency, among other cardiovascular diseases. However, with the objective of reducing the incidence of this disease, several pharmacological and nonpharmacological strategies have been implemented to prevent, treat, and reduce hypertension (Hernández and Anderson, 2012).

In this last respect, several foods have been identified that may help to reduce diseases, with milk and dairy products being the most widely studied (Shiby and Mishra, 2013). Furthermore, over the last 3 decades, milk-derived peptides have been identified with potential antihypertensive effect. These peptides may inhibit the angiotensin-converting enzyme (ACE), which prevents the formation of angiotensin II, a potent vasoconstrictor.

Several lactic acid bacteria have been reported to release potential antihypertensive peptides by the process of milk fermentation (Korhonen and Pihlanto, 2006). For instance, Rodríguez-Figueroa et al. (2010, 2012) fermented milk with specific strains of Lactococcus lactis and evaluated the ACE inhibitory activity in vitro. Results demonstrated that fermentation conditions and proteolytic activity of L. lactis for the production of ACE inhibitory peptides were strain dependent. Moreover, fermented milk with L. lactis NRRL-B50571 reduced systolic blood pressure (SBP) and diastolic blood pressure (DBP), heart rate, and had a hypolypidemic effect on spontaneously hypertensive rats (Rodríguez-Figueroa et al., 2013a,b). According to this, fermented milk with $L$. lactis NRRL B-50571 might have a hypotensive effect on hypertensive patients. Therefore, the aim of this work was to evaluate, in a randomized, placebo-controlled, double-blind study, the blood pressure-lowering effect of fermented milk with NRRL B-50571 on prehypertensive subjects.

\section{MATERIALS AND METHODS}

\section{Subjects}

A total of 60 volunteers aged from 25 to 55 yr were screened for enrollment at the Research Center for Food 
and Development (Spanish acronym: CIAD), Unilíder University, Caffenio Co., and Camino Nuevo School. A total of 36 subjects (20 men and 16 women) fulfilled the eligible criteria to participate (see Figure 1 for participant flowchart). Before screening, volunteers were given detailed information about the clinical study, and those willing to participate gave their voluntary written consent. Participant screening was performed at CIAD; and tests included medical clinical history, weight and height, laboratory tests on blood and urine, and blood pressure measurements. Blood pressure was measured in 3 separate visits. Inclusion criteria were both sexes, with SBP 120 to $139 \mathrm{mmHg}$ and 80 to $85 \mathrm{mmHg}$ for DBP (prehypertensive, JNC 8; Bell et al., 2015). Exclusion criteria were pregnancy, cardiovascular diseases, diabetes, cancer, dairy allergy, or lactose intolerance, and patients receiving ACE inhibitor pharmacological therapy. Nine volunteers were treated with antihypertensive medicines and were randomly allocated in both groups; their dosage did not change during this trial.
Volunteers were asked not to make diet and lifestyle changes.

\section{Study Design}

All subjects gave their informed consent for inclusion before they participated in the study. The study was conducted in accordance with the Declaration of Helsinki (1975) as revised in 1983, and the protocol was approved by the Bioethics Committee of CIAD, Hermosillo, Sonora, Mexico (CE/003/2013).

This study was designed as a randomized, placebocontrolled, double-blind study. Personnel unaware of the treatment assignments performed all procedures (blood and urine samples and blood pressure measurements). A run-in period before the study started took place for baseline measurements and for randomization. Measurements included: blood pressure, total cholesterol, low-density lipoproteins (LDL), high-density lipoproteins (HDL), and triglycerides (TG). Based on

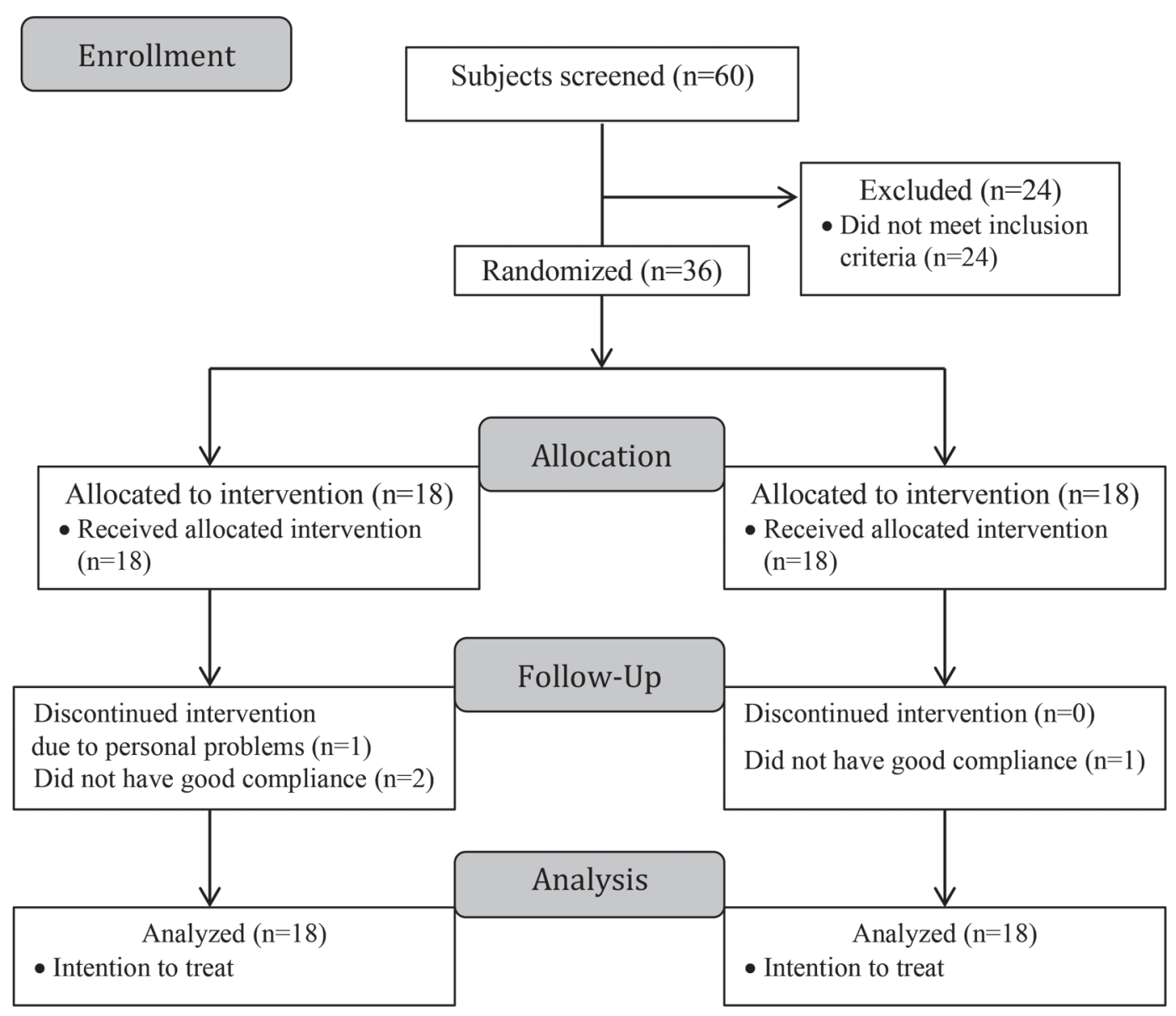

Figure 1. Participant inclusion flow chart. 
these screening data, a blinded investigator randomly allocated subjects stratified by sex (by a computer program) to the treatments and checked that there were no significant differences $(P>0.05)$ between defined groups. Volunteers were also blinded to either receive $150 \mathrm{~mL}$ of the fermented milk product $(\mathbf{F M} ; \mathrm{n}=18$; as treatment group) or $150 \mathrm{~mL}$ of the control (CON; n $=18$; as control group) daily for 8 wk. Compliance to treatment was monitored by interviewing the subjects during weekly visits. Personal who took blood pressure measurements were also blinded to treatments. The trial was registered at clinicaltrials.gov as NCT02670811, "Antihypertensive Effect of Fermented Milk With Lactococcus lactis on Prehypertensive Subjects."

\section{Supplementary Drinks}

Fermented milk was prepared as previously reported (Rodríguez-Figueroa et al., 2013a,b) with modifications. Reconstituted 10\% commercial skim milk was pasteurized, inoculated with $3 \%$ Lactococcus lactis NRRL B-50571, and fermented at $30^{\circ} \mathrm{C}$ for $48 \mathrm{~h}$. Fermentation was stopped by applying heat treatment $\left(75^{\circ} \mathrm{C}, 15 \mathrm{~min}\right)$ followed by quick cooling. Meanwhile, the control skim milk was also pasteurized and artificially acidified with lactic acid (Faga Lab, México) until pH 4.3 was reached. Fermented milk or the acidified milk were mixed with natural fruit puree $(6 \% \mathrm{wt} / \mathrm{wt})$ and sweetened with stevia (0.5\%, wt/wt; Svetia, México City, México) for the manufacture of the fermented milk product or the control. Total protein (method 960.52; AOAC International, 2000), calcium, magnesium, potassium (EPA 3052), total fat (method 989.04; AOAC International, 2000), and lactose (method 930.28; AOAC International, 2000) contents were evaluated in the fermented milk product and the control (Table 1).

Table 1. Nutritional composition (mean \pm SD of fermented milk product and control ${ }^{1}$

\begin{tabular}{lcc}
\hline Nutrient & Fermented milk product & Control product \\
\hline Lactose (g) & $3.28 \pm 0.1^{\mathrm{a}}$ & $4.39 \pm 0.2^{\mathrm{b}}$ \\
Protein (g) & $3.21 \pm 0.2^{\mathrm{c}}$ & $3.26 \pm 0.7^{\mathrm{c}}$ \\
Fat (g) & $\mathrm{ND}^{2}$ & $\mathrm{ND}$ \\
Calcium (mg) & $109 \pm 1.4^{\mathrm{d}}$ & $107 \pm 4.9^{\mathrm{d}}$ \\
Sodium (mg) & $46 \pm 1.6^{\mathrm{e}}$ & $43.2 \pm 1.3^{\mathrm{e}}$ \\
Phosphorus (mg) & $76.3 \pm 1.2^{\mathrm{f}}$ & $75.2 \pm 1.5^{\mathrm{f}}$ \\
Iron (m) & $0.07 \pm 0.5^{\mathrm{g}}$ & $0.08 \pm 0.3^{\mathrm{g}}$ \\
Magnesium (mg) & $11.7 \pm 0.2^{\mathrm{h}}$ & $11.1 \pm 0.3^{\mathrm{h}}$ \\
Potassium (mg) & $143 \pm 2.2^{\mathrm{i}}$ & $142 \pm 3.0^{\mathrm{i}}$ \\
\hline
\end{tabular}

${ }^{\mathrm{a}-\mathrm{i}}$ Values within a row followed by the same superscript are not significantly different $(P>0.05)$.

${ }^{1}$ Composition per $100 \mathrm{~mL}$.

${ }^{2} \mathrm{ND}=$ not detectable.

\section{Outcome Measures}

Once treatment began, blood pressure was measured every week. The personnel blinded to treatment assignments measured blood pressure on the right arm with a mercurial sphygmomanometer (Hergom, México City, México) with subjects in a sitting position after a 5 min rest. Measurements were taken at the same time between 0900 and $1000 \mathrm{~h}$, once a week in CIAD. Volunteers were asked not to drink coffee or treatment drinks $8 \mathrm{~h}$ before blood pressure measurements. After first blood pressure was measured, a second measurement was taken after 2 min apart. If blood pressure values differed more than $>5 \mathrm{mmHg}$, a third measurement was performed (Pickering et al., 2005). After the study ended, blood pressure was measured for 2 more weeks to see if there was any residual effect (postobservation). Lipid serum analysis (total cholesterol, LDL, HDL, and TG) were performed before treatment began and after 8 -wk intervention. Volunteers were asked to fast for at least $8 \mathrm{~h}$ before blood serum measurements. Serum biochemical indexes (LDL, HDL, and TG) were analyzed using Randox commercial kits (Randox Laboratories, Crumlin, UK) in Spinlab equipment (Spinreact, México City, México).

\section{Sample Size}

Sample size was calculated based on Kajimoto et al. (2002) study. Authors evaluated the antihypertensive effect of fermented milk during an 8-wk intervention. Assuming a 2-tailed analysis with $\alpha$ set at 0.05 and a standard deviation of $10.55 \mathrm{mmHg}$ of SBP, 22 participants (11 per group) were estimated to provide $80 \%$ power to detect a difference of $13 \mathrm{mmHg}$ of SBP between groups. However, assuming a potential 33\% dropout, we increased the number of participants to 36 (FM group, $\mathrm{n}=18$; CON group, $\mathrm{n}=18$ ).

\section{Statistical Analysis}

Baseline SBP and DBP were defined as the mean of the values measured in the first 2-wk run-in period. The blood pressure outcomes for every week are presented as the mean value with standard deviations for all participants in each group, as well for blood serum biochemical indices. We applied intention to treat analysis for those participants who were unsuccessful in compliance to treatment and those who withdraw from the study. The outcomes between groups were analyzed using an independent sample Student's $t$-test, with a $P$ value of 0.05 or less (2-sided) for statistical significance; paired Student's $t$-test was used to analyzed differences 
Table 2. Clinical characteristics (mean $\pm \mathrm{SD}$ ) of the 2 groups $^{1}$

\begin{tabular}{lccc}
\hline Item & CON group & FM group & $P$-value \\
\hline Sex (no.) & 8 & 8 & 1.00 \\
Women & 10 & 10 & \\
Men & $44.6 \pm 9.21$ & $40.5 \pm 11.7$ & 0.24 \\
Age (yr) & $85.8 \pm 18.2$ & $80.5 \pm 14.6$ & 0.34 \\
Weight (kg) & $1.67 \pm 0.11$ & $1.63 \pm 0.10$ & 0.42 \\
Height (m) & $31 \pm 5.6$ & $30.1 \pm 4.2$ & 0.56 \\
Body mass index & $134.3 \pm 7$ & $131.8 \pm 5.6$ & 0.25 \\
SBP (mmHg) & $89.3 \pm 5.8$ & $87.7 \pm 5.1$ & 0.36 \\
DBP (mmHg) & $178.1 \pm 26$ & $190.1 \pm 43.6$ & 0.32 \\
Total CHOL (mg/dL) & $114.7 \pm 26$ & $127.1 \pm 43$ & 0.30 \\
LDL (mg/dL) & $37.8 \pm 6.5$ & $37.9 \pm 8.7$ & 0.97 \\
HDL (mg/dL) & $144.3 \pm 63.5$ & $137.5 \pm 42.3$ & 0.70 \\
TG (mg/dL) & & & \\
\hline
\end{tabular}

${ }^{1} \mathrm{CHOL}=$ cholesterol; DBP $=$ diastolic blood pressure; HDL = high-density lipoproteins; LDL = low-density lipoproteins; $\mathrm{SBP}=$ systolic blood pressure; $\mathrm{TG}=$ triglycerides.

from baseline, with a $P$-value of 0.05 or less $(2$-sided) for statistical significance, using Stata statistical software (version 11, StataCorp., College Station, TX).

\section{RESULTS AND DISCUSSION}

\section{Supplementary Drinks}

Nutritional composition corresponding to FM and CON is presented in Table 1. The FM was not significantly different $(P>0.05)$ for all nutrients, except for lactose content. Intervention and epidemiologic studies have suggested an inverse relationship between calcium intake and blood pressure (McCarron and Morris, 1985). Milk contains a considerable amount of calcium and other micronutrients (sodium, phosphorus, iron, magnesium, and potassium). However, we use the same commercial skim milk to prepare artificially acidified and fermented milks; thus, the micronutrient content was not different in both drinks (Table 1). Although both drinks (fermented milk and acidified milk) had a blood pressure-lowering effect by the fifth week, fermented milk had a greater $(P<0.05)$ effect on SBP $(116.55 \pm 12.26 \mathrm{mmHg}$ vs. $124.77 \pm 11.04 \mathrm{mmHg})$ than $\mathrm{CON}$; therefore, the hypotensive effect may be attributed to components other than calcium.

\section{Compliance and Side Effects}

Thirty-six men and women were randomized to either receive FM or placebo treatment. After treatment began, only 1 participant of the FM group withdrew by the second week. Two other volunteers from the FM group and 1 volunteer from the CON group did not have compliance to treatment. Nevertheless, volunteers were asked to participate in the measurements of the outcomes. Therefore, no data were missing and this study was analyzed with intention to treat, where blood pressure was taken weekly to all 36 subjects.

\section{Subject Characteristics}

Twenty men and 16 women with blood pressure higher than 130/85 for SBP and DBP were eligible for randomization (Table 2). No significant differences $(P$ $>0.05)$ were observed between groups on clinical and biochemical characteristics (age, weight, height, body mass index, blood pressure, and cholesterol levels).

\section{Blood Pressure}

In the present study, the blood pressure-lowering effect of fermented milk with L. lactis NRRL B-50571 in prehypertensive subjects was demonstrated. Changes in SBP and DBP are depicted in Figure 2. Results showed that SBP and DBP from the FM group presented lower values than the CON group, throughout all the intervention. Furthermore, SBP from the FM group was significantly lower $(P<0.05)$ than that from the CON group by the third $(120.11 \pm 11.44 \mathrm{mmHg}$ vs. $127.16 \pm 8.26 \mathrm{mmHg})$ and fifth week $(116.55 \pm 12.26$ $\mathrm{mmHg}$ vs. $124.77 \pm 11.04 \mathrm{mmHg}$ ). After the intervention ended, there was a 2 -wk follow-up. It was observed that decrements on SBP and DBP were maintained only 1 wk after the treatment was terminated. Nevertheless, after the second week without treatment, blood pressure tended to gradually increase. Hence, to maintain the blood pressure-lowering effect, this fermented milk must be taken daily. Similar findings have been reported in several studies with fermented milks, where there was a tendency to return to its initial blood pressure value after the treatment was discontinued for 1 to 2 wk (Hata et al., 1996; Hirata et al., 2002; Kajimoto et al., 2002; Nakamura et al., 2004). 
Additionally, SBP and DBP from the FM group decreased significantly $(P<0.05)$ from baseline. The SBP decreased from 9.33 to $15.27 \mathrm{mmHg}$ for the FM group and DBP decreased from 4 to $7.27 \mathrm{mmHg}$. It has been reported that any blood pressure reduction is meaningful because SBP reduction of 10 to $12 \mathrm{mmHg}$ and DBP reduction of $5 \mathrm{mmHg}$ may reduce risk by $40 \%$ for stroke, $16 \%$ for coronary disease, and $13 \%$ for all causes of mortality (Jäkälä and Vapaatalo, 2010). Additionally, in a prospective study, it was reported that decreases of $2 \mathrm{mmHg}$ reduced incidence of 26.6 times for heart failure events, 17.9 times for coronary heart disease, and 9.6 times for stroke (Hardy et al., 2015). Framingham Heart Study investigators also reported that a reduction of $2 \mathrm{mmHg}$ on $\mathrm{DBP}$ is associated with $17 \%$ decrease in the prevalence of hypertension, $15 \%$ reduction risk in stroke, and $6 \%$ reduction risk in coronary heart disease (Cook et al., 1995). Moreover, blood pressure-related deaths in prehypertensive subjects indicated that approximately one-third of coronary heart disease can be attributed to elevated SBP (Stamler et al., 1993). In this regard, it is important that blood pressure reduction interventions be not only focused on hypertensive subjects, but also on prehypertensive subjects.

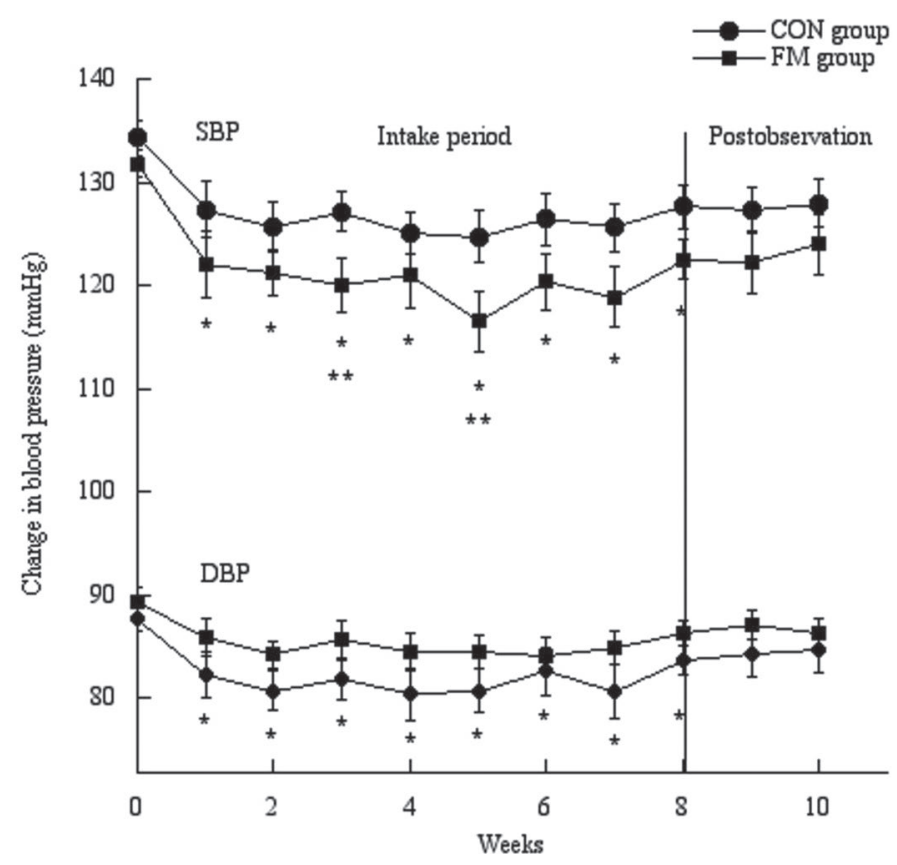

Figure 2. Changes of systolic blood pressure and diastolic blood pressure. Mean $( \pm$ SEM), from baseline during the 8 -wk treatment and 2-wk follow-up. $\mathrm{CON}=$ control; $\mathrm{DBP}=$ diastolic blood pressure; FM $=$ fermented milk; SBP $=$ systolic blood pressure. ${ }^{*}$ Significant different from baseline $(P<0.05)$ paired Student's $t$-test. ${ }^{* *}$ Significant different between FM group and CON group $(P<0.05)$ unpaired Student's $t$-test.
It should be noted that this is the first clinical trial reported with blood pressure-lowering effect of fermented milk with Lactococcus lactis NRRL B-50571 on prehypertensive subjects. In a previous study, 21 new encrypted milk peptides from fermented milk with L. lactis NRRL B-50571 with ACE inhibitory activity were identified. In fact, a hypotensive lactotripeptide IPP was identified encrypted in this fermented milk (HPHPHLSFMAIPP and SLPQNIPPL; RodríguezFigueroa et al., 2012). It has been widely reported that IPP has an antihypertensive effect in spontaneously hypertensive rats (SHR; Masuda et al., 1996; Sipola et al., 2001; Sipola et al., 2002; Jauhiainen et al., 2005a) and hypertensive subjects (Hata et al., 1996; Hirata et al., 2002; Kajimoto et al., 2002; Seppo et al., 2003; Nakamura et al., 2004; Mizushima et al., 2004; Jauhiainen et al., 2005b); nevertheless, other new milk peptides were identified (Rodríguez-Figueroa et al., 2012). Additionally, fermented milk with L. lactis NRRL B-50571 was administered to spontaneously hypertensive rats. It was concluded that fermented milk with this strain had a hypotensive and hypolipidemic effect (RodríguezFigueroa et al., 2013b). In another study, a single dose of a water-soluble extract from fermented milk with L. lactis NRRL B-50571 had a hypotensive and heartrate-lowering effect (Rodríguez-Figueroa et al., 2013a). Thus, it was concluded that in this clinical study the blood pressure-lowering effect of the fermented milk may potentially be attributed to the ACE-inhibitory effect of the peptides. Nevertheless, other potential mechanisms may be involved, such as antioxidant, opioid effect, or nitric oxide production (Kim et al., 2010; Marques et al., 2012; Majumder and Wu, 2014; Udenigwe and Mohan, 2014). Henceforth, it is necessary to evaluate other possible mechanisms through in vivo studies with spontaneously hypertensive rats.

\section{Serum Lipids}

Serum lipids changes are shown in Table 3. After 8 wk of treatment, total cholesterol, LDL cholesterol, and TG were lower in the FM group than in the CON group, although differences were not significant $(P>0.05)$. It is well reported that elevated blood cholesterol, mainly LDL, increases the risk of coronary diseases. Hence, the first priority is to reduce LDL as a main goal to decrease coronary diseases, as well as reducing risks of metabolic syndrome (Expert Panel on Detection, Evaluation, and Treatment of High Blood Cholesterol in Adults, 2001).

It is important to acknowledge that people suffering with dyslipidemia may develop cardiovascular diseases. Because dyslipidemia causes endothelial damage, it may be one factor in the development of hypertension 
Table 3. Serum lipids (mean $\pm \mathrm{SD}$ ) after treatment with fermented milk $(\mathrm{FM})$ or control $(\mathrm{CON})^{1}$

\begin{tabular}{lcccc}
\hline Treatment & Total CHOL $(\mathrm{mg} / \mathrm{dL})$ & LDL $(\mathrm{mg} / \mathrm{dL})$ & HDL $(\mathrm{mg} / \mathrm{dL})$ & TG $(\mathrm{mg} / \mathrm{dL})$ \\
\hline FM group & $180.66 \pm 36.12^{\mathrm{a}}$ & $116.6 \pm 37.8^{\mathrm{b}}$ & $43.2 \pm 8.1^{\mathrm{c}}$ & $103.6 \pm 44.3^{\mathrm{d}}$ \\
CON group & $189.8 \pm 39.10^{\mathrm{a}}$ & $122.7 \pm 31.8^{\mathrm{b}}$ & $42.4 \pm 7.6^{\mathrm{c}}$ & $124.9 \pm 56.0^{\mathrm{d}}$ \\
\hline${ }^{\mathrm{a}-\mathrm{d}}$ Values within a column followed by the same superscript are not significantly different $(P>0.05)$. \\
${ }^{1} \mathrm{CHOL}=$ cholesterol; HDL $=$ high-density lipoproteins; LDL = low-density lipoproteins; TG $=$ triglycerides.
\end{tabular}

(Halperin et al., 2006). Several cross-sectional studies suggest a link between dyslipidemia and hypertension (Hunt et al., 1991; Haffner et al., 1996; Oparil et al., 2003). Additionally, it is well reported that individuals with higher blood pressure tend to have higher serum cholesterol levels (Castelli and Anderson, 1986). Although volunteers in this did not present dyslipidemia, it is important to evaluate this disease in another clinical trial focusing on the hypolipidemic effect of this fermented milk.

\section{CONCLUSIONS}

In conclusion, because the control of cardiovascular diseases is multifactorial, interventions should not only aim to reduce blood pressure, but also be designed to reduce cholesterol (LDL) and TG levels. Fermented milk with L. lactis NRRL B-50571 attenuated blood pressure and improved cholesterol levels in prehypertensive subjects. Because SBP was lower in the fermented milk group than in the control group, the administration of fermented milk with L. lactis NRRL B-50571 may provide heart health benefits. Although DBP and serum cholesterol values were lower in the fermented milk group than in the control, differences were not significant; nevertheless, it may be considered noteworthy from a physiological health point of view. Reduction of blood pressure and serum cholesterol levels are necessary to achieve a reduction in the incidence of other cardiovascular diseases. Hence, daily consumption of fermented milk with L. lactis NRRL B-50571 may be used as a potential functional food.

\section{ACKNOWLEDGMENTS}

The authors thank the participants for their dedication and hard work throughout the trial. We thank Bertha I. Pacheco Moreno, Ana Cristina Gallegos and Monica Soto for their valuable help measuring blood pressure, and Ricardo Reyes-Díaz for preparing and handling samples. The authors' responsibilities were as follows: BVC, JER, and ETI designed the study; LMBB conducted the study and wrote the manuscript; JER performed the randomization and the statistical analysis; BVC revised the manuscript and had primary responsibility for the final content of the manuscript; AFGC, AHM, and HAG supplied valuable knowledge and scientific consultation throughout the study; and all authors read and approved the final manuscript. The authors hereby declare no conflict of interests. This study was supported by the Mexican Council of Science and Technology (CONACYT; México City, Mexico) research project 240338 CONACYT. CONACYT had no role in the design of the study; in the collection, analyses, or interpretation of data; in the writing of the manuscript, or in the decision to publish the results.

\section{REFERENCES}

AOAC International. 2000. Official Methods of Analysis. 17th ed. AOAC International, Gaithersburg, MD.

Bell, K., J. Twiggs, and B. R. Olin. 2015. Hypertension: The Silent Killer: Updated JNC-8 Guideline Recommendations; Alabama Pharmacy Association; Summer 2015: continuing education.

Castelli, W. P., and K. Anderson. 1986. A population at risk: Prevalence of high cholesterol levels in hypertensive patients in the Framingham study. Am. J. Med. 80:23-32.

Cook, N. R., J. Cohen, P. R. Hebert, J. O. Taylor, and C. H. Hennekens. 1995. Implications of small reductions in diastolic blood pressure for primary prevention. Arch. Intern. Med. 155:701-709.

Expert Panel on Detection, Evaluation, and Treatment of High Blood Cholesterol in Adults. 2002. Third Report of the National Cholesterol Education Program (NCEP) Expert Panel on Detection, Evaluation, and Treatment of High Blood Cholesterol in Adults (Adult Treatment Panel III) final report. Circulation 106:31433421.

Haffner, S., H. Miettinen, S. Gaskill, and M. Stern. 1996. Metabolic precursors of hypertension: The San Antonio Heart Study. Arch. Intern. Med. 156:1994-2001.

Halperin, R., H. Sesso, J. Ma, J. Buring, M. Stampfer, and J. Gaziano. 2006. Dyslipidemia and the risk of incident hypertension in men. Hypertension 47:45-50.

Hardy, S., L. R. Loehr, K. R. Butler, S. Chakladar, P. P. Chang, A. R. Folsom, G. Heiss, R. F. MacLehose, K. Matsushita, and C. L. Avery. 2015. Reducing the blood pressure-related burden of cardiovascular disease: Impact of achievable improvements in blood pressure prevention and control. J. Am. Heart Assoc. 4:e002276.

Hata, Y., M. Yamamoto, M. Ohni, K. Nakajima, Y. Nakamura, and T. Takano. 1996. A placebo-controlled study of the effect of sour milk on blood pressure in hypertensive subjects. Am. J. Clin. Nutr. 64:767-771.

Hernández, J., and S. Anderson. 2012. Prehypertension: A literaturedocumented public health concern. J. Am. Acad. Nurse Pract. 24:3-10.

Hirata, H., Y. Nakamura, H. Yada, S. Moriguchi, O. Kajimoto, and T. J. Takahashi. 2002. Clinical effects of new sour milk drink on mild or moderate hypertensive subjects. J. New Rem. Clin. 51:61-69.

Hunt, S., S. Stephenson, P. Hopkins, and R. Williams. 1991. Predictors of an increased risk of future hypertension in Utah. A screening analysis. Hypertension 17:969-976. 
Jäkälä, P., and H. Vapaatalo. 2010. Antihypertensive peptides from milk proteins. Pharmaceuticals 3:251-272.

Jauhiainen, T., M. Collin, M. Narva, T. Paussa, and R. Korpela. 2005a. Effect of long-term intake of milk peptides and minerals on blood pressure and arterial function in spontaneously hypertensive rats. Milchwissenschaft 60:358-362.

Jauhiainen, T., H. Vapaatalo, T. Poussa, S. Kyrönpalo, M. Rasmussen, and R. Korpela. 2005b. Lactobacillus helveticus fermented milk lowers blood pressure in hypertensive subjects in 24-h ambulatory blood pressure measurement. Am. J. Hypertens. 18:1600-1605.

Kajimoto, O., T. Kurosaki, J. Mizutani, N. Ikeda, K. Kaneko, K. Aihara, M. Yabune, and Y. Nakamura. 2002. Antihypertensive effects of liquid yogurts containing "lactotripeptides (VPP, IPP)" in mild hypertensive subjects. Nutr. Food. 5:55-66.

Kim, S. M., S. Park, and R. Choue. 2010. Effects of fermented milk peptides supplement on blood pressure and vascular function in spontaneously hypertensive rats. Food Sci. Biotechnol. 19:14091413.

Korhonen, H., and A. Pihlanto. 2006. Bioactive peptides: Production and functionality. Int. Dairy J. 16:945-960.

Majumder, K., and J. Wu. 2014. Molecular targets of antihypertensive peptides: Understanding the mechanisms of action based on the pathophysiology of hypertension. Int. J. Mol. Sci. 16:256-283.

Marques, C., M. Amorim, J. O. Pereira, M. E. Pintado, D. Moura, C. Calhau, and H. Pinheiro. 2012. Bioactive peptides-Are there more antihypertensive mechanisms beyond ACE inhibition? Curr. Pharm. Des. 18:4706-4713.

Masuda, O., Y. Nakamura, and T. Takano. 1996. Antihypertensive peptides are present in aorta after oral administration of sour milk containing these peptides to spontaneously hypertensive rats. J. Nutr. 126:3063-3068.

McCarron, D. A., and C. D. Morris. 1985. Blood pressure response to oral calcium in person with mild to moderate hypertension. Ann. Intern. Med. 103:825-831.

Mizushima, S., K. Ohshige, J. Watanabe, M. Kimura, T. Kadowaki, and Y. Nakamura. 2004. Randomized controlled trial of sour milk on blood pressure in borderline hypertensive men. Am. J. Hypertens. 17:701-706.

Nakamura, Y., O. Kajimoto, K. Kaneko, K. Aihara, J. Mizutani, N. Ikeda, A. Nishimura, and Y. Kajimoto. 2004. Effects of the liquid yogurts containing "lactrotripeptide" (VPP, IPP) on high-normal blood pressure. J. Nutr. Food. 7:123-137.

Oparil, S., M. Zaman, and A. Calhoun. 2003. Pathogenesis of hypertension. Ann. Intern. Med. 139:761-776.

Pickering, T. G.. J. E. Hall, L. J. Appel, B. E. Falkner, J. Graves, M. N. Hill, D. W. Jones, T. Kurtz, S. G. Sheps, and E. J. Roccella.
2005. Recommendations for blood pressure measurement in humans and experimental animals. Part 1: Blood pressure measurement in humans. Hypertension 45:142-161.

Rodríguez-Figueroa, J. C., A. F. González-Córdova, H. AstiazaránGacía, and B. Vallejo-Córdoba. 2013a. Hypotensive and heart rate lowering effects in rats receiving milk fermented by specific Lactococcus lactis strains. Br. J. Nutr. 109:827-833.

Rodríguez-Figueroa, J. C., A. F. González-Córdova, H. AstiazaránGacía, and B. Vallejo-Cordoba. 2013b. Antihypertensive and hypolipidemic effect of milk fermented by specific Lactococcus lactis strains. J. Dairy Sci. 96:4094-4099.

Rodríguez-Figueroa, J. C., A. F. González-Córdova, M. J. TorresLlanez, H. S. García, and B. Vallejo-Cordoba. 2012. Novel angiotensin I-converting enzyme inhibitory peptides produced in fermented milk by specific wild Lactococcus lactis strains. J. Dairy Sci. 95:5536-5543.

Rodríguez-Figueroa, J. C., R. Reyes-Díaz, A. F. González-Córdova, R. Troncoso-Rojas, I. Vargas-Arispuro, and B. Vallejo-Cordoba. 2010. Angiotensin-converting enzyme inhibitory activity of milk fermented by wild and industrial Lactococcus lactis strains. J. Dairy Sci. 93:5032-5038

Seppo, L., T. Jauhiainen, T. Poussa, and R. Korpela. 2003. A fermented milk high in bioactive peptides has a blood pressure-lowering effect in hypertensive subjects. Am. J. Clin. Nutr. 77:326-330.

Shiby, V. K., and H. N. Mishra. 2013. Fermented milks and milk products as functional foods: A review. Crit. Rev. Food Sci. Nutr. 53:482-496.

Sipola, M., P. Finckenberg, R. Korpela, H. Vapaatalo, and M. Nurminen. 2002. Effect of long-term intake of milk products on blood pressure in hypertensive rats. J. Dairy Res. 69:103-111.

Sipola, M., P. Finckenberg, J. Santisteban, R. Korpela, H. Vapaatalo, and M. Nurminen. 2001. Long term intake of milk peptides attenuates development of hypertension in spontaneously hypertensive rats. J. Physiol. Pharmacol. 52:745-754.

Stamler, J., R. Stamler, and J. D. Neaton. 1993. Blood pressure, systolic and diastolic, and cardiovascular risks. US population data. Arch. Intern. Med. 153:598-615.

Udenigwe, C., and A. Mohan. 2014. Mechanisms of food proteinderived antihypertensive peptides other than ACE inhibition. J. Funct. Foods 8C:45-52.

WHO. 2013. World Health Organization. A global brief on hypertension. Silent killer, global public health crisis. Accessed Apr. 12, 2014. http://www.thehealthwell.info/node/466541. 